\title{
Ola Forsans, Le Théâtre de Lélio: étude du répertoire du Nouveau Théâtre Italien de 1716 à 1729
}

\section{Paola Perazzolo}

\section{(2) OpenEdition}

1 Journals

\section{Edizione digitale}

URL: http://journals.openedition.org/studifrancesi/9207

DOI: 10.4000/studifrancesi.9207

ISSN: 2421-5856

\section{Editore}

Rosenberg \& Sellier

\section{Edizione cartacea}

Data di pubblicazione: 1 juin 2008

Paginazione: 184-185

ISSN: 0039-2944

\section{Notizia bibliografica digitale}

Paola Perazzolo, «Ola Forsans, Le Théâtre de Lélio: étude du répertoire du Nouveau Théâtre Italien de 1716 à 1729», Studi Francesi [Online], 154 (LII | I) | 2008, online dal 30 novembre 2015, consultato il 13 janvier 2021. URL: http://journals.openedition.org/studifrancesi/9207 ; DOI: https://doi.org/10.4000/

studifrancesi.9207

Questo documento è stato generato automaticamente il 13 janvier 2021.

\section{(c)}

Studi Francesi è distribuita con Licenza Creative Commons Attribuzione - Non commerciale - Non opere derivate 4.0 Internazionale. 


\title{
Ola Forsans, Le Théâtre de Lélio: étude du répertoire du Nouveau Théâtre Italien de 1716 à 1729
}

\author{
Paola Perazzolo
}

\section{NOTIZIA}

OLA FORSANS, Le Théâtre de Lélio: étude du répertoire du Nouveau Théâtre Italien de 1716 à 1729, Oxford, Voltaire Foundation, 2006 («SVEC 2006: 8»), pp. 378.

1 Tratto da una tesi di dottorato discussa nel 2002, il presente volume ha innanzitutto il merito di far conoscere meglio un momento finora trascurato ma importante del teatro francese del diciottesimo secolo. Penalizzato da un pregiudizio critico duro a morire che considera il repertorio della troupe degli Italiani come un insieme di opere leggere e di puro divertissement cui solo il genio di Marivaux ha talvolta conferito un più alto valore letterario, il nuovo teatro diretto per più di una decina d'anni da Luigi Riccoboni, in arte Lélio, rappresenta invece un momento rilevante per l'evoluzione del gusto e della sensibilità letteraria del secolo. Risultato della fusione tra le diverse tradizioni teatrali francese ed italiana, il repertorio messo in scena all'Hôtel de Bourgogne tra il 1716 e il 1729 si impone per la sua novità, riscontrabile non solo dal punto di vista del linguaggio drammatico, dei giochi scenici, dei temi e delle forme adottati, ma anche delle idee annunciate, idee 'moderne' che talvolta anticipano quelle dei philosophes. L'autore, che si è già occupato di questo argomento curando l'edizione di tre commedie di Delisle (Arlequin sauvage, Timon le misanthrope, Les caprices du coeur et de l'esprit), articola il suo lavoro in modo chiaro ed esaustivo.

Una prima presentazione storico-sociale ricorda il passato della vecchia troupe così come l'arrivo, la composizione e l'evoluzione del gruppo diretto da Riccoboni, offre la lista degli spettacoli messi in scena in più di dieci anni, e ritraccia il panorama teatrale della Parigi dell'epoca, per meglio evidenziare la novità e l'originalità della concezione 
artistica di Lélio. Segue una seconda parte, più incentrata sulla «fabrique des comédies», per esplicitare i meccanismi di costruzione tipici di questo teatro, a livello di scrittura come di resa sul palcoscenico. Dal punto di vista prettamente teatrale il critico rievoca l'abitudine ai lazzi e ai giochi scenici, punto di forza e caratteristica peculiare degli Italiens, la divisione dei ruoli, meno stereotipata di quanto non si creda, e l'abitudine ad una gestualità marcata che non contrasta tuttavia con la volontà di adottare una recitazione 'naturale', ben diversa da quella più artificiosa della ComédieFrançaise. Dal punto di vista della scrittura, vengono analizzati i testi e i loro paratesti, l'uso dei dialoghi e dei monologhi, i meccanismi di sviluppo e progressione di intrecci sicuramente all'insegna della leggerezza, dell'attenzione ai moti del cuore, al lato allegro e spensierato dell'esistenza, ma che celano ad un più attento esame una riflessione vivace e acuta sulla profondità dell'essere umano, sui meccanismi sociali, sull'estetica e la sensibilità di un mondo in cambiamento - quello della Parigi della Reggenza - di cui gli Italiens rispecchiano valori e sentimenti. Questo è quello che l'autore esplicita anche nella sua terza parte, «L'esprit du Théâtre de Lélio», rievocando puntualmente influenze e corrispondenze tra forme teatrali diverse e sottolineando le continuità tematiche e stilistiche del repertorio italiano di questo decennio.

Nonostante gli importanti volumi consacrati all'argomento da Xavier de Courville qualche decennio fa, la critica ha finora scarsamente considerato l'avventura teatrale e poetica legata al Nuovo Teatro Italiano, soffocato dall'eccessiva attenzione rivolta al solo Marivaux, il cui astro avrebbe offuscato quello di tutti gli altri autori, e da molti pregiudizi critici. Grazie ad un lavoro attento e puntuale di ricostruzione storica, letteraria, sociale ed artistica, Ola Forsans mostra invece come il repertorio del «Théâtre de Lélio» sia innovativo e originale e come contribuisca, ben più di quello dei teatri direttamente concorrenti - la Comédie Française e i forains -, allo sviluppo e al mutamento della sensibilità e dei modelli estetico-letterari della prima metà del Settecento. 